\title{
sciendo
}

\section{Preliminary computational and experimental design studies of the ISHTAR thermostatic rig for the high-temperature reactors materials irradiation}

Anna Talarowska $\mathbb{1 0}^{\circ}$ Maciej Lipka $\mathbb{0}^{\circ}$, Grzegorz Wojtania

\begin{abstract}
The Irradiation System for High-Temperature Reactors (ISHTAR) thermostatic rig will be used to irradiate advanced core material samples in conditions corresponding to those prevailing in the high-temperature reactors (HTRs): these conditions include a stable temperature extending up to $1000^{\circ} \mathrm{C}$ in the helium atmosphere. Computational and experimental studies concerning the design have been conducted, proving the possibility of these conditions' fulfillment inside the rig while maintaining the safety limits for MARIA research reactor. The outcome is the thermostatic rig design that will be implemented in the MARIA reactor. Appropriate irradiation temperature will be achieved by a combination of electric heating with the control system, gamma heating, and a helium insulation gap with precisely designed thickness. The ISHTAR rig will be placed inside the vertical irradiation channel, which is located in the reactor pool. The device is being developed from scratch at the Nuclear Facilities Operation Department of the National Centre for Nuclear Research as a part of the GOSPOSTRATEG programme.
\end{abstract}

Keywords: High-temperature reactor $\bullet$ HTR $\bullet$ Irradiation $\bullet$ Materials $・$ Reactor MARIA

A. Talarowska ${ }^{凶}$, M. Lipka, G. Wojtania

National Centre for Nuclear Research

Andrzeja Sołtana 7 Str., 05-400 Otwock-Świerk, Poland

E-mail: anna.talarowska@ncbj.gov.pl

Received: 4 January 2021

Accepted: 7 February 2021

\section{Introduction}

MARIA is a channels-in-pool type, water-cooled research reactor, located in the National Centre of Nuclear Research (NCBJ) in Otwock-Świerk, Poland. It has a nominal power of $30 \mathrm{MW}_{\text {th }}$ with a core containing $20+$ individually cooled fuel elements located in pressure tubes. Neutron moderation is provided by beryllium blocks and light water [1]. The reactor is used for a broad scope of irradiation programmes and experimental studies. Its design with vertical irradiation channels located in the beryllium matrix enables the installation of a broad range of research devices in the core and flexible switching of their locations between the reactor operation cycles.

As the high-temperature reactors (HTRs) seem to be considered by the Polish government as a meaningful branch of scientific studies in the field of nuclear energy [2, 3], the need for the development of thermostatic rig that will enable irradiations in the HTR conditions emerged. As a result of this interest, a state-funded research programme named GOSPOSTRATEG was initiated, which in its part is aimed at the development of methods for testing of structural materials in a nuclear research reactor [4]. The programme considered the development of

0029-5922 @ 2021 The Author(s). Published by the Institute of Nuclear Chemistry and Technology.

This is an open access article under the CC BY-NC-ND 4.0 licence (http://creativecommons.org/licences/by-nc-nd/4.0/). 
a high-temperature thermostatic reactor rig aimed at the irradiation of materials related to the development of HTR technology.

Such thermostatic rigs are irradiation devices (capsule-like) with built-in temperature control systems that are dedicated to individual research goals. They are used in both existing and currently built research reactors [5-8], and, as research reactors differ from each other, the design is required to be in line with individual design features of the specific reactor. After irradiation, the material samples undergo various tests, including scanning electron microscopy (SEM), Raman spectroscopy, and $\mathrm{X}$-ray diffraction. Testing methodology prefigured for graphite samples is precisely described in another work [9]. Since graphite is an essential material for the construction of HTRs, it was chosen as the initiating one. The irradiation time of the samples is predicted for several cycles of the MARIA research reactor; however, the exact time may change since it depends on the current core configuration. Although this rig is designed for one irradiation round, the competencies built in that project allow the designers to adapt the rig design for diverse material samples.

Historically, irradiation rigs have been designed and operated in MARIA in the 1970s and 1980s, (GAPISZON, MAK, KRS-M, KAMELEON, and several members of KAMA family) with operating temperatures up to $200^{\circ} \mathrm{C}$ and used for other types of research $[9,10]$. Unfortunately, the competencies associated with these rigs were mostly lost due to the generation gap after the political turmoil of 1989 and the 30 years of limited interest in nuclear power generation; consequently, they had to be rebuilt with a lot of effort and time for the occasion of the current project.

\section{Design assumptions and initial calculations}

As part of GOSPOSTRATEG programme, a probe named Irradiation System for High-Temperature Reactors (ISHTAR) was designed to provide conditions comparable with what is expected in HTRs. Those assumptions include providing irradiation of material specimens at temperatures up to $1000^{\circ} \mathrm{C}$ surrounded by helium atmosphere inside the rig. Material specimens were provided by Materials Research Laboratory and contained selected types of graphite dedicated for destructive testing planned to be performed in the laboratory.

Additionally, it was assumed that the samples of loading volume have to be as large as possible and external cooling will be provided by the MARIA reactor pool cooling system. Those assumptions have led to certain design constraints:

- The helium gap will serve as the rig thermal insulation.

- Heating will be provided by a combination of electrical power and gamma heating.

- The rig will be inserted into the largest irradiation channel in the MARIA reactor with internal diameter $d=54 \mathrm{~mm}$ and cooled by forced water circulation in the pool.
- Heat transfer in axial direction has to be minimalized to homogenize temperature inside the rig.

- For the same purpose, graphite was chosen to serve as the sample's holder, as it possesses sufficiently high thermal conductivity.

Based on the points presented above, initial one-dimensional calculations in axisymmetric geometry have been performed to obtain ISHTAR dimensions for further, exact computational fluid dynamics (CFD) optimization analyses and technical design.

It was assumed that temperature in the radial direction changes according to Eq. (1) written in finite volumes approximation, derived from the one-dimensional heat transfer equation with an internal heat source, in axisymmetric geometry [11].

$$
\frac{1}{r_{j}} \cdot \frac{1}{r}\left[\left(\lambda r \frac{\partial T}{\partial r}\right)_{r_{i+1 / 2}}-\left(\lambda r \frac{\partial T}{\partial r}\right)_{r_{i-j / 2}}\right]+\dddot{q}=0
$$

where $\lambda\left(\mathrm{W} \cdot \mathrm{m}^{-1} \cdot \mathrm{K}^{-1}\right)$ represents thermal conductivity, $\ddot{q}\left(\mathrm{~W} \cdot \mathrm{m}^{-3}\right)$ volumetric heat generation, $j(-)$ radial coordinate of the finite volume, $r$ and $\Delta r(\mathrm{~m})$ radial coordinate and radial layer thickness, respectively, and $T\left({ }^{\circ} \mathrm{C}\right)$ temperature.

Heat transfer via natural convection mechanism in helium insulation gap was reduced to equivalent thermal conductivity described by Eq. (2) [12].

$$
\lambda_{e}=\lambda\left(T_{m}\right)_{\mathrm{He}} \cdot C \cdot(\mathrm{Gr} \cdot \mathrm{Pr})^{n}
$$

where $C, n(-)$ represent natural circulation parameters gathered in Table 1, Gr (-) represents temperature-dependent helium's Grasshof number, $\operatorname{Pr}(-)$ temperature-dependent helium's Prandtl number, $T_{m}\left({ }^{\circ} \mathrm{C}\right)$ average temperature between hot and cold wall of the helium gap, $\lambda_{e}\left(\mathrm{~W} \cdot \mathrm{m}^{-1} \cdot \mathrm{K}^{-1}\right)$ equivalent thermal conductivity of helium in natural convection conditions, and $\lambda\left(T_{m}\right)_{\mathrm{He}}\left(\mathrm{W} \cdot \mathrm{m}^{-1} \cdot \mathrm{K}^{-1}\right)$ helium thermal conductivity in $T_{m}$ temperature, which is given by the approximate formula presented in Eq. (3) [12]

$$
\lambda\left(T_{m}\right)_{\mathrm{He}}=3.13952 \cdot 10^{-4} \cdot T_{m}+1.46262 \cdot 10^{-1}
$$

Finally, radiation heat transfer in the helium gap was modelled as two additional heat fluxes with absolute values being equal: negative on the hot (internal) wall and positive on a cold (external) wall, as described by Eqs. (4),(5) [11].

$$
Q_{1-2}=A \cdot \sigma \cdot \varepsilon_{1-2} \cdot\left(T_{\text {in }}^{4}-T_{\text {out }}^{4}\right)
$$

where $A\left(\mathrm{~m}^{2}\right)$ represents cylindrical wall area, $T_{\text {in }}$ and $T_{\text {out }}(\mathrm{K})$ inner and outer wall of helium gap, respectively, $\varepsilon_{1-2}(\mathrm{~W})$ equivalent emissivity, and $\sigma$ $\left(\mathrm{W} \cdot \mathrm{m}^{-2} \cdot \mathrm{K}^{-4}\right)$ Stefan-Boltzmann constant.

$$
\varepsilon_{1-2}=\left(\frac{1}{\varepsilon_{\text {in }}}+\frac{1}{\varepsilon_{\text {out }}} \cdot \frac{1}{\varepsilon_{\text {out }}}\right)
$$

Table 1. Natural convection parameters [12]

\begin{tabular}{lccc}
\hline \multirow{2}{*}{$\mathrm{Gr} \cdot \mathrm{Pr}$} & $<10^{3}$ & $10^{3}-10^{6}$ & $10^{6}-10^{10}$ \\
\hline $\mathrm{C}$ & 1 & 0.105 & 0.4 \\
$\mathrm{~N}$ & 0 & 0.3 & 0.2 \\
\hline
\end{tabular}


where $r_{\text {in }}$ and $r_{\text {out }}(\mathrm{m})$ represent inner and outer helium gap walls diameters, respectively, $\varepsilon_{\text {in }}$ and $\varepsilon_{\text {out }}$ (W), respectively, inner and outer helium gap walls emissivity, given for ANSI316 steel by Eq. (6) [13].

$$
\varepsilon=1.81818 \cdot 10^{-4}+2.00545 \cdot 10^{-1}
$$

Finally, the heat transfer coefficient had to be specified. For that purpose, a linear pressure drop in the external hydraulic mockup of the reactor channel has been measured. As the geometric dimensions were known, it was relatively easy to determine the coolant velocity from the formula (7), together with Reynolds (Eq. (8)), and Nusselt number approximated by Gnielinski formula (9) [11]. Finally, from formula (10), heat transfer coefficient at the rig cooled wall was calculated within the range $h=$ 8000-10 $000\left(\mathrm{~W} \cdot \mathrm{m}^{-2} \cdot \mathrm{K}^{-1}\right)$. Results of the series of pressure drop vs. volumetric flow measurements are presented in Fig. 1.

$$
\begin{gathered}
w=\sqrt{\frac{2 \cdot d_{h}}{L \cdot f} \frac{p}{\rho}} \\
\operatorname{Re}=\frac{w \cdot d_{h}}{\vartheta} \\
\mathrm{Nu}=\frac{(f / 8) \cdot(\mathrm{Re}-1000) \cdot \mathrm{Pr}}{1+12.7 \cdot(f / 8)^{1 / 2} \cdot\left(\mathrm{Pr}^{2 / 3}-1\right)} \\
h=\frac{\mathrm{Nu} \cdot \lambda}{d_{h}}
\end{gathered}
$$

where $d_{h}(\mathrm{~m})$ represents hydraulic diameter, $f(-)$ Darcy friction factor, $h\left(\mathrm{~W} \cdot \mathrm{m}^{-2} \cdot \mathrm{K}^{-1}\right)$ heat transfer coefficient, $L(\mathrm{~m})$ the distance between the measurement points, $\Delta p(\mathrm{~Pa})$ linear pressure drop, $w\left(\mathrm{~m} \cdot \mathrm{s}^{-1}\right)$ coolant flow velocity, $\mathrm{Nu}(-)$ Nusselt number, $\mathrm{Re}(-)$ Reynolds number, $\lambda\left(\mathrm{W} \cdot \mathrm{m}^{-1} \cdot \mathrm{K}^{-1}\right)$ water thermal conductivity, $\rho\left(\mathrm{kg} \cdot \mathrm{m}^{-3}\right)$ coolant density, and $\vartheta\left(\mathrm{m} \cdot \mathrm{s}^{-2}\right)$ water kinematic viscosity.

For initial calculation, a simple MATLAB-based code was created. As it was iterative, the convergence threshold was set as specified under the formula (11). Additionally, the simple capability to calculate the construction materials' linear thermal expansion in the radial direction was implemented as per the formula (12) [14].

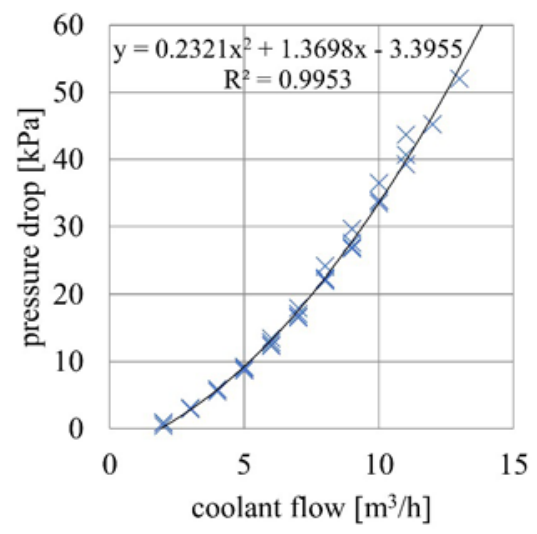

Fig. 1. Results of the pressure drop vs. coolant flow measurement in the mockup of the irradiation channel.

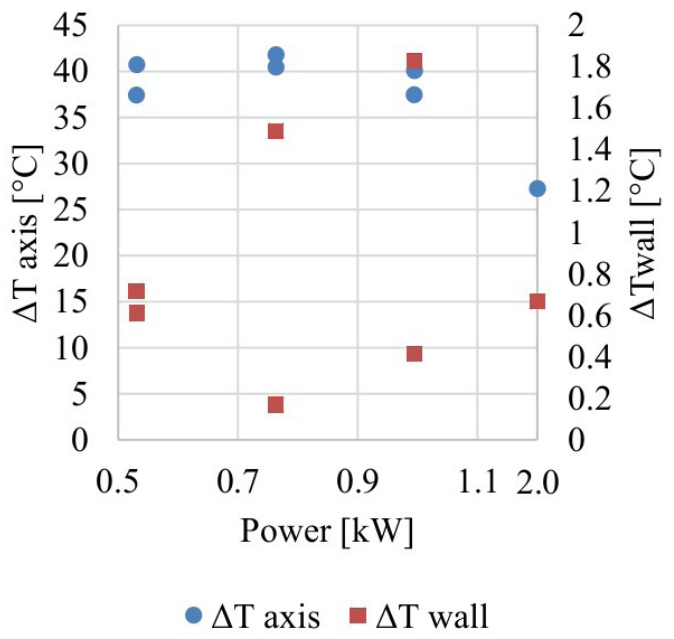

Fig. 2. One-dimensional code validation. Measured to computed temperature differences as a function of the rig power. Note that the last point on the horizontal axis is out of the scale.

$$
\begin{gathered}
\left|T_{\max }(n+1)-T_{\max }(n)\right| \leq 10^{-9} \\
r=r_{0} \cdot \alpha \cdot T
\end{gathered}
$$

where $\Delta r(\mathrm{~m})$ represents change of radius size, $r_{0}(\mathrm{~m})$ radius in the cold, initial state, $\Delta T\left({ }^{\circ} \mathrm{C}\right)$ temperature increase, $T_{\max }\left({ }^{\circ} \mathrm{C}\right)$ maximum temperature in the rig, $n(-)$ iteration number, and $\alpha=1.75 \times 10^{-7}$ $\left(1 \times{ }^{\circ} \mathrm{C}^{-1}\right)$ coefficient of linear thermal expansion for ANSI316 steel.

Code numerical results were validated in the mentioned-above hydraulic mockup of the irradiation channel, for the several levels of electrical power in the heater; results are presented in Fig. 2. Despite the code limitations (one-dimensional, in a highly three-dimensional case of heat transfer, reduced natural convection, and thermal radiation heat transfer mechanism), the calculation results were in a relatively good agreement relative to the measurement: axis temperature and wall differences amounted to $45^{\circ} \mathrm{C}$ and $2^{\circ} \mathrm{C}$, respectively. Due to the electric heater limitations, a power higher than $2 \mathrm{~kW}$ could not be achieved during the experiment.

Results of the calculation are presented in Fig. 3. We surmise from the figure that the temperature level $T=1000^{\circ} \mathrm{C}$ is capable of being achieved in the rig region that is filled with the material samples. Initial necessary gap thickness was calculated to be

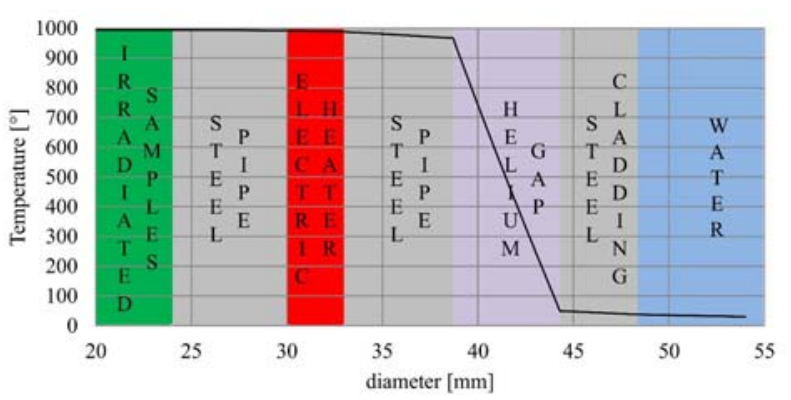

Fig. 3. Result of the 1D heat transfer calculation of the ISHTAR rig. The dimensions of the layers in the radial direction are marked approximately. 
$D_{\text {cold }}=3.15 \mathrm{~mm}$, and due to the thermal expansion shrinks to $D_{\text {hot }}=2.9 \mathrm{~mm}$ during the rig operation.

The initial parameters of the calculation were: $h=10000 \mathrm{~W} \cdot \mathrm{m}^{-2} \cdot \mathrm{K}^{-1}$ - heat transfer coefficient; $P_{e l}=9800 \mathrm{~W} \cdot \mathrm{m}^{-1}-$ linear density of electric power; $P_{\gamma}=1.0 \mathrm{~W} \cdot \mathrm{g}^{-1}-$ gamma heating; $\mathrm{T} w=30^{\circ} \mathrm{C}-$ cooling water temperature.

Calculation results were the starting point for design and careful optimization described in the next two sections. The key issue was optimizing axial insulation along the rig to minimize the heat sink at the active part where the material samples are located. It was the iterative process arising due to manufacturing limitations of the ceramics and assembly of the irradiation rig.

\section{Description of the ISHTAR rig design}

The main goal of the ISHTAR probe was to demonstrate the possibility of graphite specimen (Fig. 4) irradiation in high temperatures. To reach this, the working section of the irradiation rig was designed according to calculation results provided in the previous and following chapters. The outcome of modelling efforts is described below.

The probe irradiates four graphite specimens of graphite samples, each $100 \mathrm{~mm}$ long (Fig. 5). The samples are fitted with six thermocouples as part of the temperature monitoring inside the probe. The specimen is implemented inside the rig's tray with loading space with cylindrical space of diameter $28 \mathrm{~mm}$ and $400 \mathrm{~mm}$ long. The tray encapsulating the loading space is wrapped in seven high-temperature heaters.

The heaters are placed in spiral grooves and interlaced at the bottom, allowing both cold ends of each heater directly upward. The heater interfaces' stainless steel sleeve tube's outer diameter allows maintaining $3.15 \mathrm{~mm}$ isolating gap between the probe tray and the probe's outer tube. The gap is
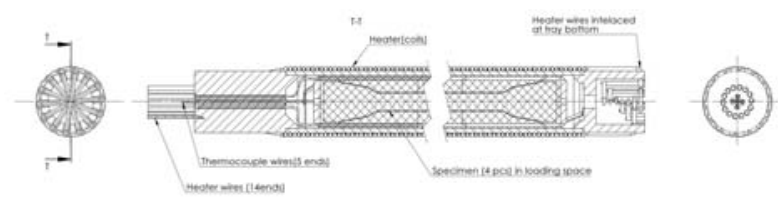

Fig. 4. Graphite specimen assembly with thermocouples attached.

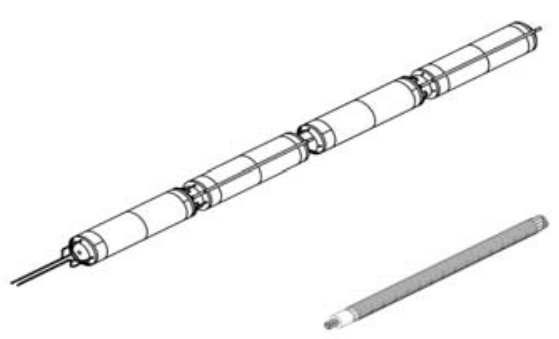

Fig. 5. Top: Isometric view of the instrumented material sample containers. Bottom: Isometric view of the electrical heater coils.

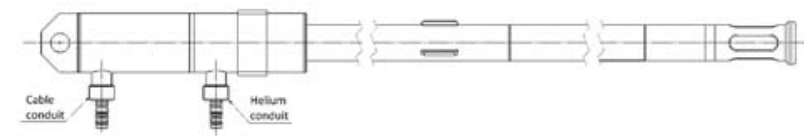

Fig. 6. ISHTAR thermostatic rig overview.

filled with helium, providing isolation necessary to reach a temperature of $900^{\circ} \mathrm{C}$ inside the tray. The upper and lower ends of the tray in the sleeve are additionally isolated by rings manufactured from zirconium-yttrium ceramic with low thermal conductivity.

The working section of the ISHTAR probe described above is planned for irradiation inside the beryllium block channel $(60 \mathrm{~mm} ; L=1100 \mathrm{~mm})$ with neutron flux maximizing in the middle of block height located in the middle of the isotopic channel. To fix the position of the working section in the middle of block height, the lower end ("foot") is welded below the working section. The lower end section centers the probe on the bottom of the channel while also minimizing flow restrictions of cooling water passing through the isotopic channel (Fig. 6).

Above the rig's working section, the distancing tube ended with connectors located in a section with wider diameter facilitating heater and thermocouple wire connections. Power and control cables from the wider section are led through the corrugated tubes and connected to the power and control cabinet located outside the reactor pool. All connections in the rig are designed and verified to be leak-tight, to maintain the helium atmosphere inside the assembly.

The rig location in the reactor core may differ as the MARIA research reactor core configuration differs with every reactor cycle, which lasts less than a week. Four possible locations are assigned: E-VI, J-IX, K-V, and K-VI (Fig. 7).
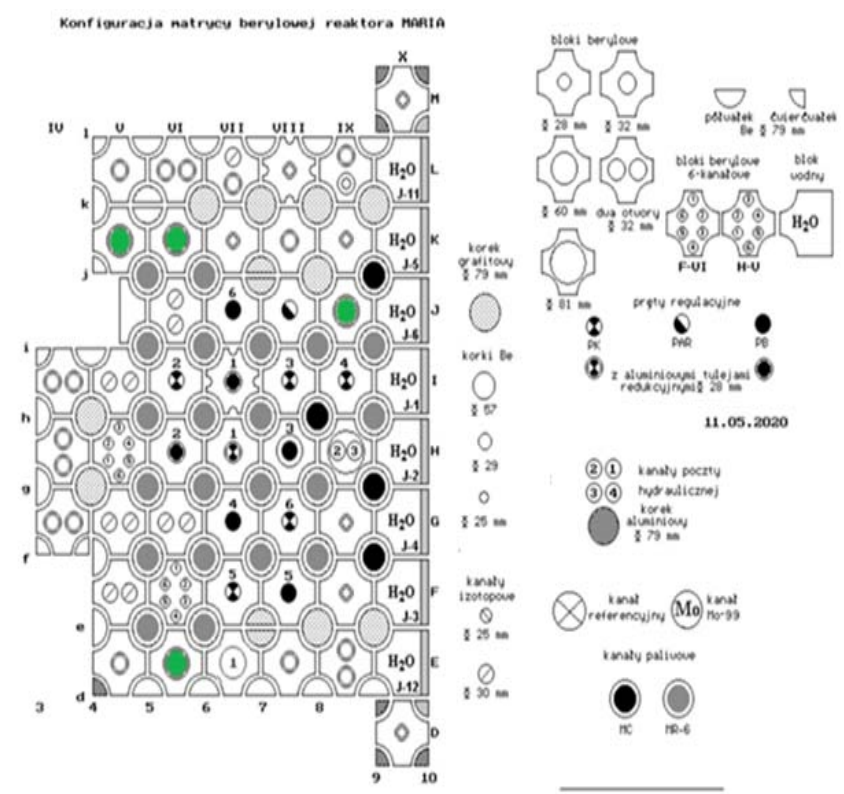

11.05.2020
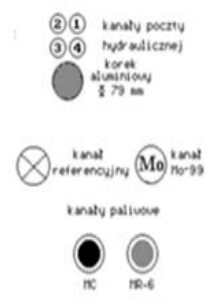

Fig. 7. Allotted irradiation locations for the ISHTAR irradiation rig in MARIA reactor core marked in green. The scheme covers the core without the reflector blocks. The fuel elements are marked with dark gray circles, e.g., j-5. 


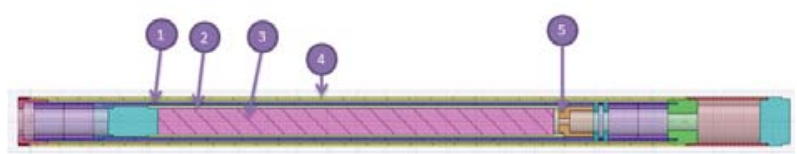

Fig. 8. Geometrical model. 1 - inner shell, 2 - electrical heater, 3 - samples with holder, 4 - outer shell, 5 - "crown".

\section{Detailed thermal optimization calculations}

The analyses aimed to determine the vertical temperature distribution in the rig and the influence of the cosine heat generation profile resulting from the interaction of gamma radiation with the rig and the optimization of the heating part's ceramic insulation along the rig axis.

The holder and the samples themselves are made of graphite with a density of $1670 \mathrm{~kg} \cdot \mathrm{m}^{-3}$ (marked in pink in Fig. 8), the electrical heater is made of nichrome, magnesium oxide, and Inconel. The heating wire is spooled on the curved stainless-steel pipe. An electrical heater is treated as a homogenous structure with carefully defined thermal properties to mimic the real structure's behaviour.

The ceramic rings act as axial insulation of the irradiation rig. Their final shape and spatial layout are a result of an iterative design and a thermal analysis process. Initially, the massive ceramics plugs were considered; however, manufacturing limitations lead to the several rings located on the very top and bottom of the irradiation rig's core part. The ceramic rings are marked in violet in Fig. 8. Other elements, namely the inner and outer shell, the top plug, and the crown are made of stainless steel. The irradiation rig's interior is filled with helium with a one-bar overpressure in relation to $7 \mathrm{~m}$ of the water column in the MARIA reactor pool.

The geometry was prepared using SpaceClaim R17.2, and then it was discretized using ANSYS Workbench Mesher 17.2; further, the computational fluid dynamics (CFD) simulation was run with ANSYS Fluent 17.2. The axisymmetric model was used to minimize the calculation time. Calculations are time-independent. The solver is a pressure-based type with SIMPLE pressure-velocity coupling. The standard differencing scheme was chosen for pressure, while momentum, turbulence, and energy are treated with the second-order upwind scheme. The calculations were performed with convergence criteria equal to $1 \times 10^{-6}$ for all residuals. The SST $k$ - $\omega$ model is used for turbulence modelling. The energy equation is enabled, and so is the radiation S2S model. Helium thermal properties are defined as a piecewise-linear function to thoroughly analyse all three modes of heat transfer, namely conduction, convection, and radiation.

The volumetric heat source was defined in each component of the rig. The sample holder was virtually cut into six parts where a slightly different heat source was defined considering the cosine shape of the nuclear heating in the reactor core. The shape of the normalized nuclear heating applied to the model is depicted in Fig. 9. It is anticipated that

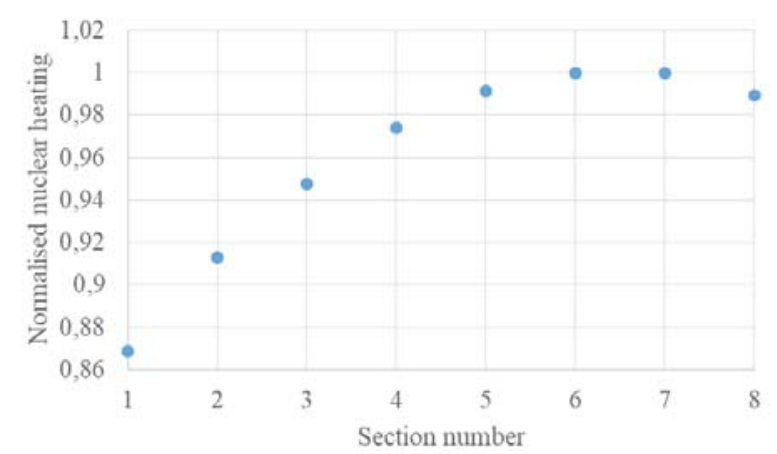

Fig. 9. Normalized nuclear heating applied to the model.

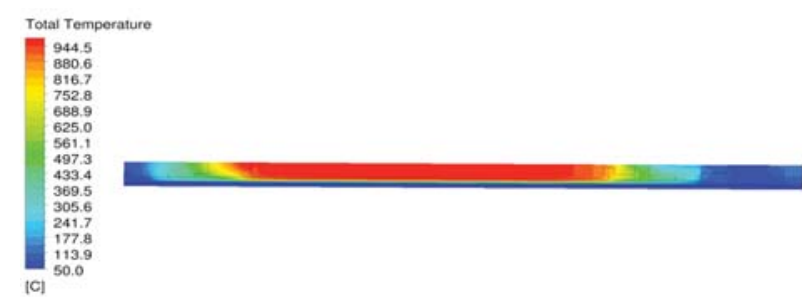

Fig. 10. Temperature field in the core part of the irradiation rig.

the maximum of nuclear heating is $1 \mathrm{~W} \cdot \mathrm{g}^{-1}$. However, the value may slightly increase due to reactor core configuration changes. This fact was included in the electrical heating power design. The power of the heater can be continuously adjusted by the controller, which collects signals from thermocouples. For $1.0 \mathrm{~W} \cdot \mathrm{g}^{-1}$ of maximum nuclear heating and $1000^{\circ} \mathrm{C}$ samples temperature, the nominal electrical power equal to $4 \mathrm{~kW}$ is predicted.

The Neumann boundary condition was applied on the outer shell and both top and bottom plugs. On the outer shell, the constant heat transfer coefficient equal to $10000 \mathrm{~W} \cdot \mathrm{m}^{-2} \cdot \mathrm{K}^{-1}$, and bulk fluid temperature equal to $50^{\circ} \mathrm{C}$, forced convection. Boundary conditions at the top and the bottom of the model are defined as a constant heat transfer coefficient $5 \mathrm{~W} \cdot \mathrm{m}^{-2} \cdot \mathrm{K}^{-1}$, and bulk fluid temperature equal to $50^{\circ} \mathrm{C}$ on the bottom and $80^{\circ} \mathrm{C}$ on the top (free convection).

The irradiation temperature of the graphite samples equals $940^{\circ} \mathrm{C}$, which is in line with the rig's operating assumptions. In the upper part, the temperature is the same as in the sample holder interior, due to a massive stainless-steel plug-in by which a significant thermal power is generated from nuclear heating. At the bottom of the sample holder, a temperature gradient of approximately. $100^{\circ} \mathrm{C}$ is observed. In fact, this gradient is anticipated to be much lower because the crown is an electrically heated element that was not taken into account in the simulation. The temperature field is shown in Fig. 10.

\section{Conclusions}

The design of the ISHTAR thermostatic rig was developed after a series of computational and experimental studies. It was proved that the design would 
be able to achieve temperature conditions specific to the HTR that, together with the MARIA reactor flux will enable testing of the sample materials. Crucial structural elements were selected from the existing series of types to speed up the production of the prototype. The initial design was carefully optimized to minimize heat flux in an axial direction and homogenize temperature field within the holder filled with material samples. The optimization process, which leads to the final axial insulation arrangement, required tight cooperation between the analysts and the designer. Moreover, ceramics manufacturing challenges were overcome in the proposed solution. To verify the calculations, construction and testing of the fully functional rig prototype is planned to measure thermal and hydraulic conditions on the external mockup of the vertical irradiation channel. The temperature in various points inside and outside of the rig will be measured to map the temperatures and compare them with calculation results. After that, the first operating rig, loaded with two types of HTR-grade graphite samples, is planned to be placed inside the core of the MARIA reactor.

Acknowledgment. We thank our colleague Marek Migdal who took over as the leader of the design task and completed it successfully. This work was supported by the National Centre for Research and Development (NCBR) as a part of the GOSPOSTRATEG programme.

\section{ORCID}

M. Lipka (D) http://orcid.org/0000-0002-7086-2138

A. Talarowska (D) http://orcid.org/0000-0002-9190-1546

\section{References}

1. Prokopowicz, R., \& Pytel, K. (2016). Determination of nuclear fuel burn-up axial profile by neutron emission measurement. Nucl. Instrum. Methods Phys. Res. Sect. A-Accel. Spectrom. Detect. Assoc. Equip., 838, 18-23. DOI: 10.1016/j.nima.2016.09.021.

2. The Council of Ministers. (2017). Strategia na rzecz Odpowiedzialnego Rozwoju do roku 2020 (z perspektywą do 2030 r.) (Strategy for Responsible Development for the period up to 2020 including the perspective up to 2030). Monitor Polski, 2017, item 260.

3. Ministry of Climate. (2020). Program polskiej energetyki jadrowej - projekt (Polish Nuclear Power Programme - draft). (2020). Available from https:// bip.mos.gov.pl/fileadmin/user_upload/bip/prawo/ inne_projekty/PPEJ/MK_Energia_jadrowa_200806_ pop_1.pdf
4. Sobkowicz, P. (2019, August 24). Scientific projects for HTR in Poland. International Framework for Nuclear Energy Cooperation. Warszawa, Poland: Infrastructure Development Working Group Workshop. Nuclear Energy Beyond Electricity. Available from https://www.ifnec.org/ifnec/upload/docs/ application/pdf/2019-09/2-2._scientific_project_for_ htr_in_poland.pdf

5. Kim, B. -G., Sohn, J. -M., \& Choo, K. -N. (2010). Development status of irradiation devices and instrumentation for material and nuclear fuel irradiation tests in HANARO. Nucl. Eng. Technol., 42(2), 203-210. DOI: 10.5516/NET.2010.42.2.203.

6. Varivtsev, A. V., Zhemkov, I. Yu., Boev, A. V., Ishunina, O. V., Naboyshchikov, Yu. V., Poglyad, N. S., \& Sharonova, M. G. (2016). Computational and experimental study of an irradiation rig with a fuel heater for the BOR-60 reactor. Nucl. Energy Technol., 2(2), 126-131. DOI: 10.1016/j.nucet.2016.05.010.

7. D'Agata, E., Döderlein, C., Tsige-Tamirat, H., Oettingen, M., \& Mutnuru, R. (2017). The neutronics scheme adopted for the HELIOS irradiation experiment in the High Flux Reactor Petten. Ann. Nucl. Energy, 101, 312-321. DOI: 10.1016/j.anucene.2016.11.017.

8. Bamber, R., Colin, C., Bignan, G., Edwards, B., Gonnier, C., \& Waldon, C. (2017). Conceptual design of test devices for the JHR tailored to the needs of the nuclear fusion community. Fusion Eng. Des., 122, 113-123. DOI: 10.1016/j.fusengdes.2017.09.003.

9. Kurpaska, L., Frelek-Kozak, M., Wilczopolska, M., Bonicki, W., Diduszko, R., Zaborowska, A., Wyszkowska, E., Clozel, M., Kosinska, A., Cieslik, I., Duchna, M., Jozwik, I., Chmurzynski, W., Olszewski, G., Zajac, B., \& Jagielski, J. (2020). Structural and mechanical properties of different types of graphite used in nuclear applications. J. Mol. Struct., 1217, 128370. DOI: 10.1016/j.molstruc.2020.128370.

10. Żyszkowski, W. (1980). Syntetyczna ocena programu budowy sond w Z-dzie IX oraz kierunek dalszej jego realizacji (Synthetic evaluation of the rigs construction programme in Department IX and the direction of its further implementation). Świerk: Instytut Badań Jądrowych. (0-163/IX/80).

11. Çengel, Y. A. (1998). Heat transfer: A practical approach. Boston, Mass: WBC McGraw-Hill.

12. Gogół, W. (1991). Wymiana ciepła: Tablice i wykresy (Heat transfer: Tables and graphs). Warszawa: Wydawnictwa Politechniki Warszawskiej.

13. Hunnewell, T. S., Walton, K. L., Sharma, S., Ghosh, T. K., Tompson, R. V., Viswanath, D. S., \& Loyalka, S. K. (2017). Total hemispherical emissivity of SS $316 \mathrm{~L}$ with simulated very high temperature reactor surface conditions. Nucl. Technol., 198(3), 293-305. DOI: $10.1080 / 00295450.2017 .1311120$.

14. Nedoseka, A. A. (2012). Fundamentals of evaluation and diagnostics of welded structures. Oxford: Woodhead Publishing Ltd. 